\title{
Endocrine-cerebro-osteodysplasia syndrome
}

INSERM

\section{Source}

INSERM. (1999). Orphanet: an online rare disease and orphan drug data base. Endocrinecerebro-osteodysplasia syndrome. ORPHA:199332

Endocrine-cerebro-osteodysplasia (ECO) syndrome is characterized by various anomalies of the endocrine, cerebral, and skeletal systems resulting in neonatal mortality. 